\title{
Topografía y localización de la ciudad de Naucratis desde la Antigüedad hasta nuestros días
}

\author{
Covadonga SeVilla Cueva*
}

\section{INTRODUCCIÓN: La geografía}

Naucratis se encuentra en la actualidad en la provincia de Bahari, «la provincia marítima", ya que recibe su nombre de el-Bahr, vocablo que significa «mar». La región ha venido sufriendo desde época faraónica los diversos cambios que han afectado a todo el delta. Entre ellos habría que mencionar la desaparición del brazo Canópico del Nilo, la desecación de los lagos, el hundimiento progresivo de la región, detectado ya desde el siglo XV de nuestra Era ${ }^{1}-y$ que percibieron tanto los miembros de la expedición francesa de Napoleón ${ }^{2}$, como los sucesivos estudiosos que pasaron por la zona hasta nuestro siglo-, y las grandes modificaciones de la hidrografía que han ido configurando una nueva fisonomía del delta. La construcción de un sistema de diques que regularizara y controlara la inundación terminó con el paisaje de un enorme lago en el que sólo emergían las ciudades como islas de un gran mar, que nos narraba Heródoto ${ }^{3}$. A principios del siglo XIX, en la Bahari y en el resto del delta, aún se cultivaba por canales de inundación. A partir de 1825, Muhammad Ali empezó a pensar en un nuevo sistema y, en 1843, mandó construir un dique sobre las dos ramas del Nilo, en el vértice del delta, en funcionamiento de modo provisional desde 1867. Junto a la construcción del dique se abrieron también nuevos canales, el más importante de los cuales, el de Katabat, corría en paralelo a la rama Roseta

\footnotetext{
* Universidad Autónoma de Madrid.

" Maqrizi: «Description, topographie et histoire de l’Égypte», traducción de U. Bouriant en Mémoires des membres de la mission archéologique française, XVII, fasc. 1, 1895; chap. XIX, p. 506.

Cordier, L: «Description des ruines de Sân (Tanis des anciens)» en Description de l'Égypte, Texte, Antiquités, Description, 2, 1818; cap. XXIII, pp. 1-18.

3 Hdt., II, 97.
} 
durante unos $80 \mathrm{kms}^{4}$. Su extensión total era de $123 \mathrm{kms}$., y desembocaba en el de Mahmudiya, cuya función era proporcionar agua dulce a Alejandría y, al mismo tiempo, regar unas 2.000 hectáreas.

Los canales existentes en la Antigüedad desaparecieron cuando se secó el brazo Canópico, y los actuales atraviesan lugares nuevos. A veces, sin embargo, alguno de ellos puede recorrer tramos del antiguo lecho del río, como es el caso de los canales de Mahmudiya o Abu-Diab.

La agricultura, que depende del régimen hidrográfico, también ha sufrido muchos cambios, sobre todo en la zona de los lagos y el litoral. Por ejemplo, Abukir que había sido muy pantanoso, hoy se ha convertido en una gran extensión cultivada. $Y$ al contrario, algunas de las explotaciones de la Antigüedad, como ciertos viñedos de Mariut, han dejado de trabajarse. Igualmente se ganó terreno al desierto tras realizar labores de irrigación en zonas que antes sólo ocupaba la arena. También conviene destacar la introducción de nuevos cultivos desde la Edad Media y más tarde, como son el arroz y el algodón, que tanta importancia tienen hoy en la alimentación y la economía del país.

Finalmente diremos que de todo el delta occidental, la región de la Bahari Central es la más fértil y la más rica. Y no sólo lo es ahora, desde el cambio del sistema de irrigación, sino también en el mundo antiguo. Esto es debido por una parte, a que estaba regada por el brazo Canópico cuyo lecho, como ya he señalado, es hoy aprovechado por el canal de Abu-Diab. Pero además, una de las ventajas de esta región es una pendiente natural que buza de Este a Oeste, y cuyo efecto era que todos los canales que derivaban antes de la rama Canópica y hoy de la Roseta, seguían esta pendiente, de modo que la abundancia del agua era lo normal ${ }^{5}$.

\section{EN TORNO A LA RAMA CANÓPICA}

En la actualidad, las dos principales ramas del Nilo en el delta son la rama Roseta en el Oeste, y la Damieta en el Este. Sin embargo, en la Antigüedad no era así; hace 3000 años, los brazos Pelusiaco al Este y Canópico al Oeste, eran los más extremos (lámina 1).

Otro de los objetivos de los científicos de la expedición francesa en Egipto fue encontrar el antiguo curso del Nilo en su rama más occidental

Barrois, J: Les irrigations en Egypte, 1904, pp. 291-308.

Bernand, A., 1970, vol. II, pp. 513-14. 




Lámina 1. Trazado de los cursos de agua en el delta del Nilo durante la época antigua (según O. Toussoun).

${ }^{6}$. Pero sería O. Toussoun quien, en 1922-23, proporcionara el recorrido más exacto y el que es hoy comúnmente aceptado ${ }^{7}$. Para él este brazo era el más importanie y comenta que Aristóteles decía que era el único natural, ya que los demás habían sido excavados por el hombre ${ }^{8}$.

Respecto al paso del río por la misma Naucratis - como nos informan algunos escritores antiguos - Heródoto o Estrabón-, O. Toussoun encontró pruebas decisivas para confirmarlo. Así, estudiando el mapa de la región se advierte la existencia de un canal importante llamado Abu-Diab que, desde Roseta a Zaw-et el-Bahr, pasa al lado y por el Oeste de Kom Gaif (nombre de uno de los poblados árabes sobre los que se asienta la antigua ciudad); justamente lo que nos dice Estrabón ${ }^{9}$ sobre el trayecto que se hacía desde Menfis a Schedia. Sin embargo, hay otro hecho que viene a confirmar el anterior: el Ministerio de Obras Públicas egipcio quiso realizar una gran vía navegable y de irrigación a través de la provincia de

\footnotetext{
6 Du Bois-Aymé, A: «Mémoire sur les anciennes branches du Nil et ses embouchures dans la mer», Descr. Eg., 1, 1809, pp. 277-90: «De la branche Canopique».

' Toussoun, O.: «La branche Canopique» en Mémoires sur les anciennes branches du Nit: époques ancienne et arabe, MIE IV, 1922-23.

$8 \quad$ O. Toussoun, op. cit., pág. 29.

9 Str. XVII, 23.
} 
Bahari, que llegara hasta Alejandría. Cuando se realizaron los estudios de nivelación, se vio que el canal de Abu-Diab y las tierras que lo bordeaban estaban más elevadas, eran más fértiles que las demás de la región y formaban una especie de loma. Según O. Toussoun, este fenómeno es común en Egipto a todos los emplazamientos con cursos de agua, a causa del limo que acarrean y que depositan en más cantidad en los terrenos vecinos, en detrimento de los que están más alejados. Concluye así, que la elevación del suelo y su fertilidad son una prueba del paso de esta rama por la región ${ }^{10}$.

Para dar una idea de la importancia que tenía este brazo del río para los antiguos, hay que decir que los nombres por los que se le ha conocido son muy significativos. El más general era el de Canópica ", puesto que en su desembocadura, la ciudad más importante era Canope. A veces - aunque más tardíamente- y por la cercanía de Heracleum, ciudad célebre por su santuario, se la llamaba Heracleótica ${ }^{12}$. Plinio el Viejo incluso la denomina rama Naucrática ${ }^{13}$. Sin embargo, tiene más interés el nombre utilizado por Ptolomeo, agathós demon, es decir, "el buen genio» ${ }^{14}$. Como dice A. Bernand, este término muestra bien el papel que jugaba este brazo del Nilo en la región. Fertilizaba la provincia, pero también llevaba a Alejandría las riquezas de Egipto, sobre todo el trigo ${ }^{15}$. Hasta tal punto se le daba importancia, que se han encontrado inscripciones en piedra, en monedas y hasta un santuario dedicado al Agathodemon en Alejandría, todo ello de época romana. De todas formas, es seguro que su culto ya se remontó a época helenística; es más, en época lágida aparece vinculado a agathé týche, la «Buena Fortuna», como su pareja divina ${ }^{16}$ con el desarrollo de una liturgia propia.

\section{LOCALIZACIÓN DE NAUCRATIS}

Los intentos de localizar la ciudad de Naucratis son muy antiguos y puede decirse que se remontan al menos a fines del siglo XVIII. Al comienzo siempre se basaban en los datos proporcionados por las fuentes

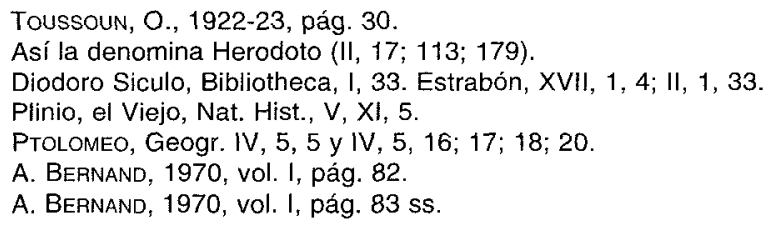


grecolatinas; una vez centrada la zona, buscaban en los topónimos contemporáneos pistas o restos del nombre antiguo que les condujeran a concretar el lugar. $Y$ de este modo, se abrió un período de hipótesis y debates que sólo culminó cuando Flinders Petrie encontró el decreto que daba nombre a la ciudad que él pretendía excavar.

Ya J.B. Bourguignon D'Anville ${ }^{17}$ rechazó en 1766 la identificación sugerida por el padre Sicard de una localidad en la orilla occidental del Nilo llamada Samokrat (Sumukhrat) con la antigua Naucratis. En su mapa, el padre Sicard había situado también Sais en la localidad de Sa. J. Bourguignon d'Anville sin embargo, creía que Sa era precisamente Naucratis, aduciendo que Estrabón había escrito que Sais estaba alejada del río.

Más tarde, el equipo científico que acompañó a Napoleón en su viaje por Egipto también se preocupó de buscar el emplazamiento de la colonia. Esta vez el error sería aún mayor, debido a que se pretendió situarla mucho más al norte, en Rahmanyat —en la entrada de un antiguo canal que llevaba a Alejandría - o en la ciudad de Kurat, más septentrional aún ${ }^{18}$. Por su parte, Muhammad el-Falaki pensó en Damanhur: «Naucratis no ha podido estar situada, conforme al testimonio de Estrabón, más que un poco por debajo de Schedia. Pues, por encima de Schedia, en el interior del país, no se ven otras colinas muy importantes que puedan anunciar el emplazamiento de una ciudad antigua muy grande como Naucratis, sobre cuyas enormes ruinas está situada actualmente la ciudad de Damanhur» ${ }^{19}$. Sin embargo, sería J.A. Letronne quien daría con la situación exacta en una nota a su traducción de la "Geografía» de Estrabón ${ }^{20}$. En ella, relacionaba el nombre de la aldea de el-Nigras con el griego de Naucratis. $Y$ fue precisamente entre esta aidea y otras cercanas donde F. Petrie descubrió la ciudad.

Parece que F. Petrie no conocía esta anotación de J.A. Letronne, puesto que en su obra ${ }^{21}$ dice que siguió los datos que facilitaban Ptolomeo y el mapa de Peutinguer (lámina 2). Aquel proporcionaba unos datos de longitud y latitud que, comparados con los datos para otros lugares vecinos, indicaban la posición del montículo de Nebire, que era donde el propio arqueólogo había estado trabajando ese año. Por otra parte, dice que el

\footnotetext{
17 Bounguignon D'ANviLLE, J.B.: Mémoires sur l'Égypte ancienne et moderne, 1766.

18 Mapa redactado por Cl. JACOTIN y M. JoMARD según el mapa topográfico del Bajo Egipto publicado en la «Description de l'Égypte», 2, 1818, al final del volumen.

19 EL-FALAKI, M.: Mémoire sur l'antique Alexandrie, 1872, pág. 82.

20 Letronne, J.A.: Geographia (de Estrabón), traduce y comenta el libro XVII (1819).

21 F. Petrie, 1886, págs. 1-10.
} 


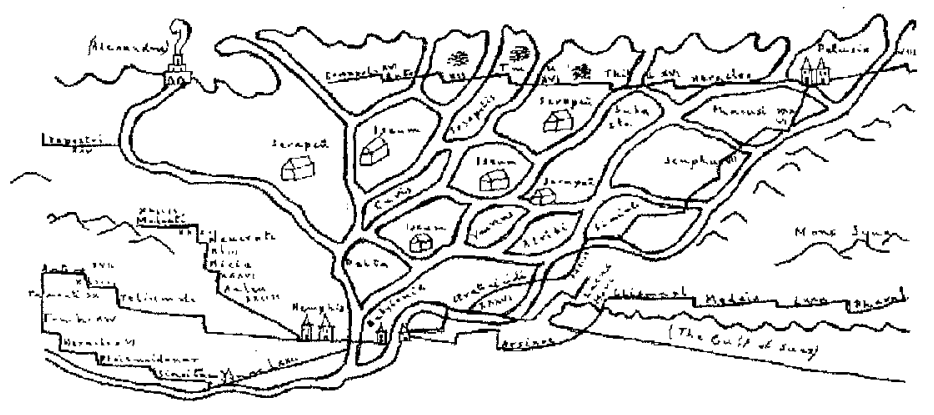

Lámina 2. El delta en la tabla Peutinguer (según Flinders Petrie).

mapa de la calzada romana conocido como Mapa o Tabla Peutinguer ${ }^{22}$, habría sido decisivo para la situación exacta, a no ser por las múltiples omisiones y erratas que presentaba, consecuencia de un mal copista ${ }^{23}$. Sin embargo, sólo confirmó que se encontraba sobre la ciudad de Naucratis el hallazgo de una piedra que servía de jamba en la entrada de la casa en la que iba a vivir y que era un decreto de la ciudad que comenzaba diciendo «La ciudad de los naucratitas... " ${ }^{24}$ (lámina 3).

Con este descubrimiento, se ponía fin a un debate que había durado más de un siglo, y del que he traído aquí las principales hipótesis. De todas formas, una vez localizada la ciudad, surgieron otros problemas derivados ya no sólo de la interpretación de los datos que proporcionaban las fuentes clásicas, sino de la evolución de la red hidrográfica del delta y de la misma exploración del asentamiento. Por ejemplo, cuál era la posición de Naucratis con respecto al río (Heródoto, Estrabón, Ptolomeo la sitúan en el brazo Canópico) es decir, si al Este o al Oeste; otro, sería averiguar si estaba al mismo borde del río o sobre un canal que partiera de él. Aquí, las opiniones también fueron variadas. F. Petrie la situaba al Oeste de la rama Canópica y en el borde de un canal. También apoyó su tesis en los testimonios de Ptolomeo y la Tabla Peutinguer. Sin embargo, cometió un error de interpretación porque quiso justificar mediante los textos lo que él creía haber observado sobre el terreno ${ }^{25}$. Pero F. LI. Griffith, colaborador

${ }_{22}$ En edición del British Museum hecha por Ortelius en 1618, y que fue hallada en manos de Cónrad Peutinguer, de quien recibe el nombre.

${ }_{23}$ F. Petrie, 1886, pág. 1-2.

24 F. Petrie, 1892, pág. 38.

25 A. Bernand, 1970, pág. 619 ss., explica detalladamente el error en que incurrió F. PETRie. Era debido sobre todo a una mala interpretación del sistema cartográfico empleado por Ptolomeo. 


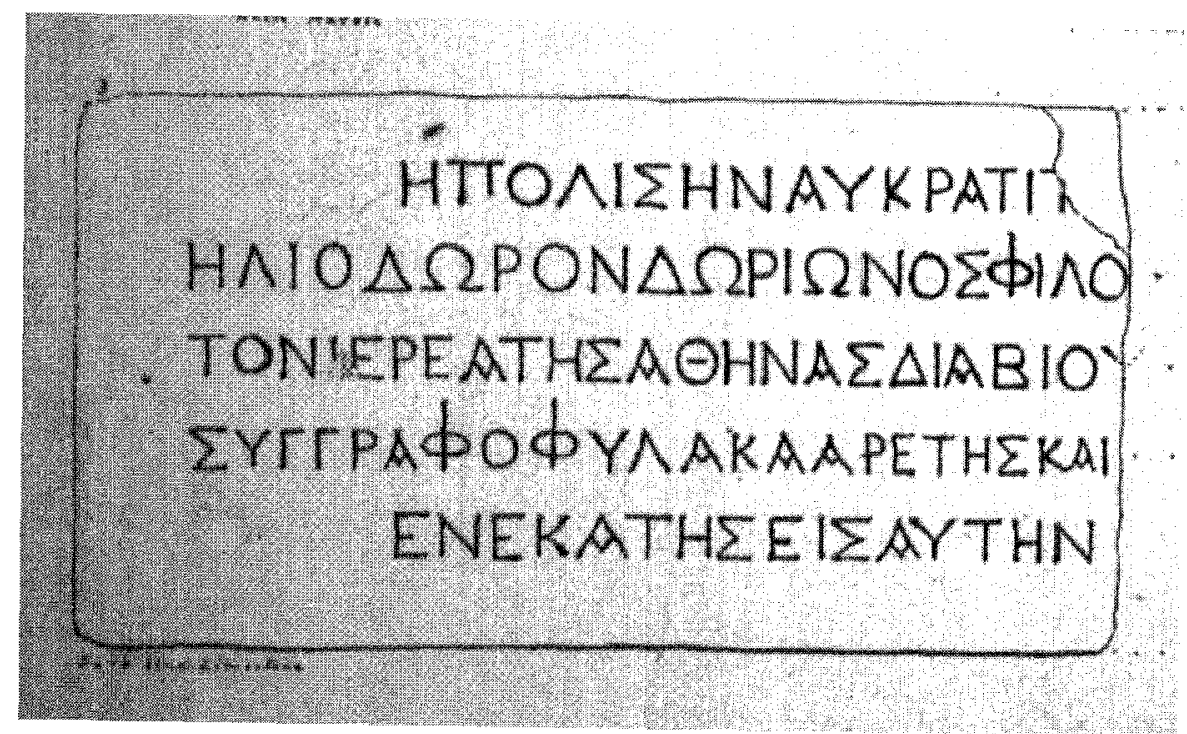

Lámina 3. Inscripción del decreto de Naucratis (según dibujo de Flinders Petrie).

de E.A. Gardner durante la segunda campaña de excavaciones, negó su tesis. Pensaba que el testimonio dado por Estrabón era decisivo, pues veía la ciudad a la izquierda, como un viajero que remontara el Nilo. De este modo, la ciudad tenía que estar al Este del mismo brazo Canópico ${ }^{26}$.

A su vez, D.G. Hogarth, intentó demostrar que no se encontraba en un canal, como había dicho F. Petrie, sino en el mismo borde del río. Para ello argumentó que Heródoto, al afirmar que la ruta desde Naucratis a Menfis por las pirámides existía sólo durante la inundación, y que la ruta habitual era la del río, no daba ningún dato para creer que había un canal. También se apoyó en otros dos documentos: un papiro copto que relataba el "Martirio del Bienaventurado Epímaco" ${ }^{27}$ en donde se dice que se transportaba al santo «al sitio llamado Naucratis y situado sobre el río...", y en la estela de Nectanebo I, cuya inscripción rezaba que la piedra se erigiría en Naucratis “... sobre la orilla del río Anu» ${ }^{28}$. Sin embargo, D.G.

26 E. A. Gardner, 1888, págs. 83-84.

${ }^{27}$ «Papyri Copti del Museo Torinese» en Me. Acad. Scienze Torino, 2. ${ }^{\text {a }}$ serie, 38, págs. 271-90.

28 Hallada por D.G. HoGARTH en el recinto del Gran Témenos de Naucratis, durante la campaña de excavaciones de 1899, aunque se notifica su existencia en la publicación de la siguiente campaña (HoGARTH, D.G., “Naukratis 1903», p. 105 ss). 
Hogarth, a pesar de que F. Griffith ya había comprobado la situación en la orilla Este, siguió insistiendo en el lado Oeste.

Esta discusión sobre el emplazamiento de Naucratis con relación al río fue aclarada por dos hechos decisivos: el descubrimiento de un papiro del siglo III a.C. que contenía una cuenta de gastos de forraje, de las sumas pagadas para pasar por los brazos del río o los canales, y de los gastos del trayecto de viajeros que venían por vía terrestre desde Pelusio a los alrededores de Alejandría ${ }^{29}$; por otra parte, el establecimiento de las curvas de nivel de la provincia de Bahari, realizados por el Ministerio de Obras Públicas egipcio ${ }^{30}$. Así pues, se vio que Naucratis estuvo situada en el lado Este del mismo brazo Canópico del Nilo, el cual en las cercanías formaba un codo y cambiaba de dirección. Se cerraba así otro de los temas más debatidos.

\section{ESTADO DEL ANTIGUO ASENTAMIENTO}

Voy aquí a referirme tan sólo a la evolución seguida por el yacimiento desde que F. Petrie comenzara a excavarlo en 1884, para dejar patente el grado de destrucción que ha venido sufriendo durante estos 110 años, prácticamente total. Cuando el arqueólogo inglés llegó a Nebire, lugar de procedencia de una estatuilla que había comprado el año anterior en el Cairo, encontró un montículo largo y bajo. La colina o kom que formaban las ruinas de Naucratis, tenía una longitud de unos $800 \mathrm{~m}$., de largo por 400 de ancho. Llevaba una dirección de Sur-Norte aunque su parte septentrional estaba ligeramente desviada hacia el Oeste. Siempre siguiendo las observaciones de F. Petrie ${ }^{31}$, parece que la superficie del montículo se encontraba a 3,60 m., por encima del suelo moderno. El arqueólogo vio en el centro de la colina un enorme agujero excavado por los habitantes de las aldeas vecinas. El motivo de este decapamiento de la parte alta era la recogida del sabaj, es decir, de los restos de los muros y estructuras de adobe que, por estar compuestas por el limo del río, eran muy adecuadas para abonar los campos (foto 1). Cuando levantaban las ruinas, los egipcios encontraban piezas que llevaban al Cairo y vendían allí o en otras zonas, a traficantes de antigüedades. Es muy posible que el área destruida por los «sabajin" fuera un tercio del $\mathrm{kom}^{32}$.

${ }^{29}$ Comentado por C.C. EDGAR en el artículo «Some hieroglyphic inscriptions from Naukratis" en ASAE, 22, 1922, p. 3.

${ }_{30}$ A. Bernand, 1970 , págs. 622-23.

31 F. PETRIE, 1886, p. 9 SS.

${ }_{32}$ W. COULSON/A. LEONARD, AJA 1982, pág. 362. 




Foto 1. El Sabaj.

Cuando al año siguiente, en 1885, E.A. Gardner se dispuso a empezar la segunda campaña de excavaciones, encontró el lugar cambiado (lámina 4). Es interesante traer aquí las citas textuales de los propios arqueólogos para ver su reacción ante estos hechos que, en el caso de E. Gardner, puede resultar tan chocante como curiosa:

"Encontramos el sitio ya cambiado por la acción devastadora de los árabes, quienes están continuamente ocupados en llevar la tierra que levantan de los sitios antiguos para esparcirla en sus campos. De esta forma, los muros del Gran Témenos o Hellenion casi habian desaparecido, y el aspecto de la colina que ocupa el lugar de la ciudad antigua había cambiado en varios sentidos. Pero al menos, si ese procedimiento es destructor, por el contrario proporciona un gran servicio al arqueólogo, porque las excavaciones de los árabes ponen constantemente al desnudo nuevos estratos y descubren nuevos sitios, de suerte que una vigilancia atenta de su trabajo y de los objetos que ellos encuentran puede a menudo aportar más informaciones que grandes y numerosos sondeos o cortes" ${ }^{33}$.

Si en un solo año el grado de destrucción fue tan elevado, cuando llegó D.G. Hogarth 14 años después encontró el lugar casi irreconocible:

33 E. A. GARDner, 1888, pág. 10. 


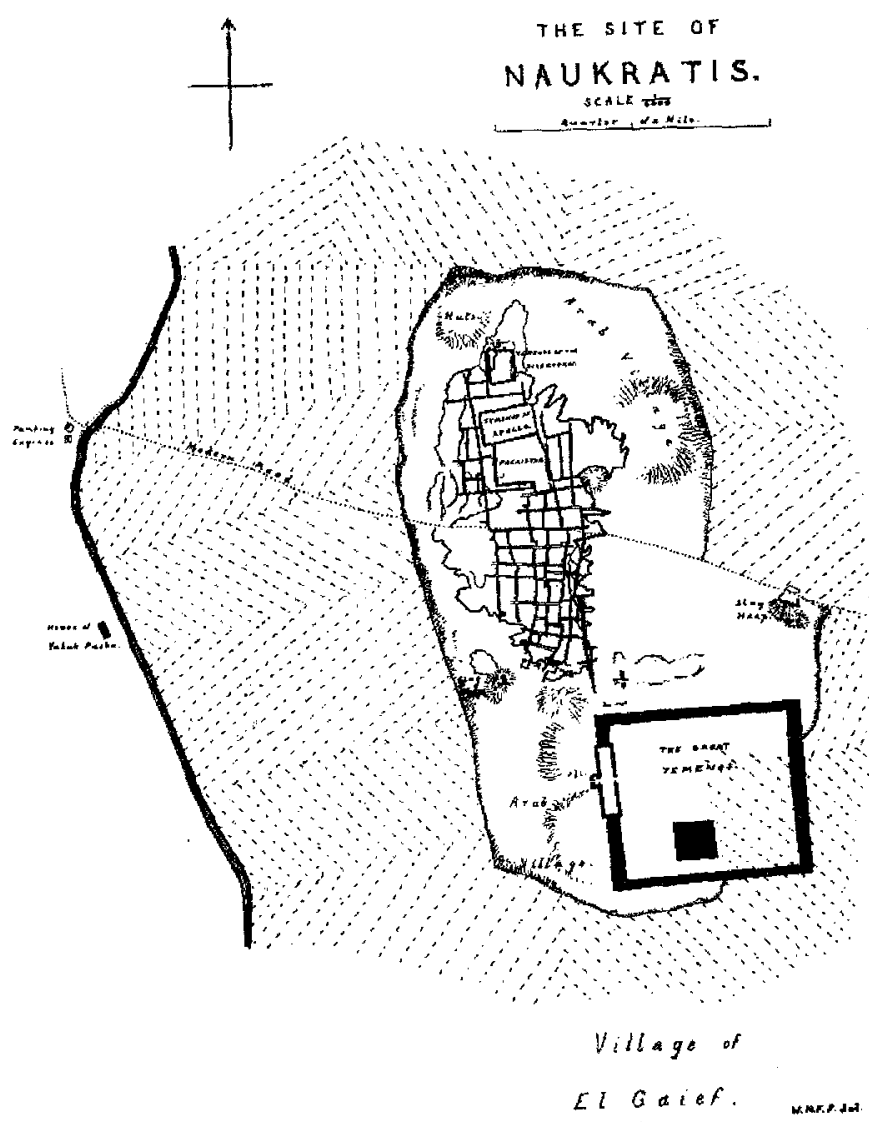

Lámina 4. Excavaciones de Naucratis en 1884/5. (Dibujo de Flinders Petrie, Naukratis I, 1886, pl. XL).

«Encontré que, comparando el mapa realizado por Petrie catorce años antes, las colinas ofrecían un aspecto muy cambiado. El "Gran Témenos», en el extremo Sur, se había convertido en un campo de trigo; la aldea árabe, indicada sobre el plano en el borde noreste de la colina, estaba ahora separada de la tierra no cultivada por una larga franja de verdor que, en el medio y al Este, había sido llevada lejos hacia el agujero del centro del sitio, gracias a un talud artificial que tenía entre 3,60 y 4,50 metros de altura aproximadamente. Cientos de indígenas se empleaban cada día para encontrar el sabaj (es decir, tierra virgen para extender sobre los campos de algodón) por todas partes en las colinas; era evidente, sin que se haya tenido de ello una prueba directa, que las grandes extensiones que en tiempos de Petrie estaban situadas arriba por encima de las tierras cultivadas, se encontraban ahora a su nivel o por debajo. Yo lo advertía particularmente en la región que se extendía 
justo al Este de los más lejanos límites septentrionales del gran agujero central (que según los indígenas fue la obra de Mr. Petrie) y donde él había situado, en este orden, la palestra, el témenos de Apolo y el de los Dioscuros: una jamba de puerta en granito, rota, tumbada a alguna distancia al Este del último témenos citado, daba testimonio de algún gran edificio, según todas las posibilidades un templo, que se habría levantado en las cercanías; y hacia el Norte se encontraban muros y capas de trozos de piedra, de los que se veía el corte, una sobre otra, en las trincheras hechas por los buscadores de abono. El conjunto del sitio parecia muy húmedo, mucho más húmedo de hecho, que lo que Mr. Petrie o Mr. Gardner habían indicado en los informes que ellos habían publicado; y más tarde, nosotros tuvimos una prueba ostensible de que la humedad había aumentado mucho desde el principio de esta usurpación, y tenía aún trazas de aumentar. Dejé las colinas de kom Ga'if convencido de que ahora o nunca debía reemprenderse su exploración, y que no había un momento que perder» ${ }^{34}$.

Cuando D.G. Hogarth volvió en 1903 para realizar la última campaña, las tareas de los sabajin habían proseguido. Sin embargo, se propuso excavar ciertas partes de algunas colinas que no había explorado en 1899 (porque o estaban muy altas, o se hallaban asoladas por las infiltraciones de agua), una vez que los buscadores del sabaj se hubieran llevado las capas superiores, improductivas, en la estación de las aguas bajas ${ }^{35}$. (Lámina 5).



Lámina 5. Plano de las cuatro campañas de excavación (Sg. H. Prinz). 
Una vez finalizada la cuarta campaña el lugar se abandonó, y no tenemos constancia por escrito de una visita a la antigua ciudad hasta 1921, en que Edith Marion Smith se acercó a Naucratis. Y sus impresiones respecto al estado del yacimiento fueron las siguientes:

«Hay dos hechos que dan cuenta del nivel actual de Naucratis. En primer lugar, el lecho del Nilo se ha levantado en torno a dos metros en relación a como era en la Antigüedad. En segundo lugar, la actividad de los sabajin (buscadores de sabaj) ha rebajado el nivel de una gran parte del sitio. La región es baja y desigual, con fuertes pendientes abruptas, montículos de escombros, y como algunas zonas están inundadas durante una gran parte del año, el sitio es húmedo y malsano.

Al Este, el suelo desciende hasta su nivel más bajo y, donde antiguamente se levantaba una parte de la ciudad, hay un estanque cuya agua viene de las tierras regadas que están por encima. Esta región más alta estaba plantada con algodón cuando yo visité el lugar en abril de 1921. Hoy, durante la estación de la inundación, igualmente algunas porciones de esta tierra más alta se encuentran bajo el agua.

Desde el punto de vista de los vestigios arqueológicos, el sitio poco puede ofrecer ahora, porque todo aquello que tenía un interés suficiente para justificar el transporte ha sido llevado a los museos hace bastante tiempo. Es posible descubrir las zonas donde las excavaciones tuvieron lugar antigüamente, pero ahora es imposible trazar las líneas de las calles o de los recintos de alguno de los templos, como pudieron hacerlo Petrie en 1885 y Hogarth en 1899 y 1903 " ${ }^{36}$.

En su recorrido, Marion Smith encontró restos de bloques de piedra por el suelo, rotos y deteriorados. Uno de ellos llevaba esculpidas dos figuras que, según afirma ella, eran de factura egipcia. Desgraciadamente no tenían inscripción y el trabajo era tosco.

Después de esta visita, la siguiente sería realizada por el doctor Zaki Ali, de la universidad de el Cairo; fue a Naucratis en 1944 y después escribió:

«Una gran parte de la antigua ciudad está ahora cubierta por el agua, pero se puede discernir sobre los bordes los restos de un muro en ladrillos rojos y probablemente los restos de un baño vecino. Dominando el sitio, hay una colina utilizada como cementerio. Este cerro de tierra tan alto y tan extenso ha desafiado la azada del excavador, y se podría creer que cubre muchos objetos interesantes" ${ }^{37}$.

Desde luego, este cementerio sigue existiendo en la actualidad y es la única zona un poco más elevada que se conserva (foto 2). Como bien

${ }_{37}$ ZAKI ALI, 1948, pág. 75. 




Foto 2. El cementerio islámico en uso y zona sur del lago.

dice el profesor Zaki Ali, sería un lugar interesante para iniciar las excavaciones de nuevo, puesto que la preservación de las tumbas ha impedido la intervención de los buscadores de sabaj. Como yo misma pude comprobar en mi visita del año 1989, en las aldeas de los alrededores, hay por doquier restos de bloques de piedra y tambores de columnas, elementos reaprovechados por los lugareños. Esto también lo observó el profesor egipcio, razón por la cual recorrió todas las aldeas en busca de restos. De este modo, obtuvo resultados interesantes:

«Hice mi última visita en enero de 1944, acompañado por el difunto profesor W.G. Waddell. En las aldeas de Kom Ga'if, Nigras, Nebire, y en los sitios vecinos, las casas estaban en parte construidas con vestigios de la antigua ciudad. Columnas, bloques de piedra y arquitrabes fueron utilizados por azar para construir las casas de campo y particularmente las mezquitas de estas aldeas. La mezquita de Nebire tenía más vestigios antiguos en herencia que cualquier otro edificio moderno de las cercanías. Los relieves, columnas, arquitrabes y bloques de piedra que ornaban o sustentaban esta mezquita había sido cogidos de los muros de la antigua ciudad. Una piedra de Naucratis que tenía una dedicatoria griega era ahora utilizada en el edificio de la mezquita. Se la extrajo de sus muros y se transfirió a la Facultad de Letras de la Universidad de Faruk... Podemos estar seguros de que otras piedras de tipo parecido han sido utilizadas para semejantes usos ${ }^{38}$.

अ ZaKI ALI, 1948, pág. 76. 
Desde 1948 ya no tenemos constancia del estado de los restos de Naucratis hasta 1977-78, en que el equipo dirigido por W. Coulson y A. Leonard inició de nuevo las excavaciones. Como se comprobará en las siguientes líneas, la zona ya se presentaba irreconocible, a no ser por la presencia del cementerio y del lago.

"La inundación, de $15 \mathrm{~m}$. de profundidad, sigue cerrando los límites del área de excavación de Petrie. Esta circunstancia sugiere que el proceso de erosión, aunque era conocido, no fue muy rápido, quizás a causa del mismo lago que, según los habitantes, existía sólo desde hace cerca de 50 años. La mayor erosión tiene lugar durante los meses de invierno, cuando el nivel de agua es el más alto, dejando trozos en los lados, especialmente a lo largo de la orilla Oeste, la más blanda, que al desplomarse, mostró una multitud de fragmentos cerámicos, principalmente de época romana. Durante los primeros meses de verano, cuando el nivel de agua pierde cerca de 3 metros, los aldeanos dicen que los muros son visibles, indicando que al menos algo de la arquitectura descubierta por los antiguos excavadores, puede estar relativamente cerca de la superficie» ${ }^{39}$.

Respecto a la zona del Gran Témenos en la que F. Petrie había llegado a ver muros de hasta $15 \mathrm{~m}$., de grosor, lo que excavaron los americanos fue un montículo (South Mound) de $60 \times 90$ m., (lámina 6), con una altura de unos $5 \mathrm{~m}$. Se podían ver aún restos de muros de adobe en la parte sureste y suroeste de esta colina.

Actualmente, kom Ga'if es el nombre de una federación de cinco aldeas, cuatro de las cuales están situadas en torno a sus orillas, mientras que la quinta, Tal Tashwan, está más retirada hacia el noroeste. El hecho de estar tan cerca del agua - Tal Abu Meshfa se encuentran tan solo a $3 \mathrm{~m}$., - indica hasta qué punto es importante este lago en la vida de estas gentes. Kom Ga'if es también el nombre del mayor de estos pueblos y a partir del cual se extendió la población, desde que F. Petrie estuvo en el lugar.

\section{SITUACIÓN ACTUAL}

Visitar Naucratis constituye hoy día una aventura, debido a que el acceso al yacimiento es muy complicado. A pesar de que desde allí se divisa la autopista que une el Cairo con Alejandría, no se pueden atravesar a pie los cientos de metros de tierras cultivadas que los separan. Así, desde Ityai el-Barud, el pueblo mayor y más cercano de los alrededores por el

39 W. Goulson/A. Leonard, J.F.A. 1979, pág. 154. 


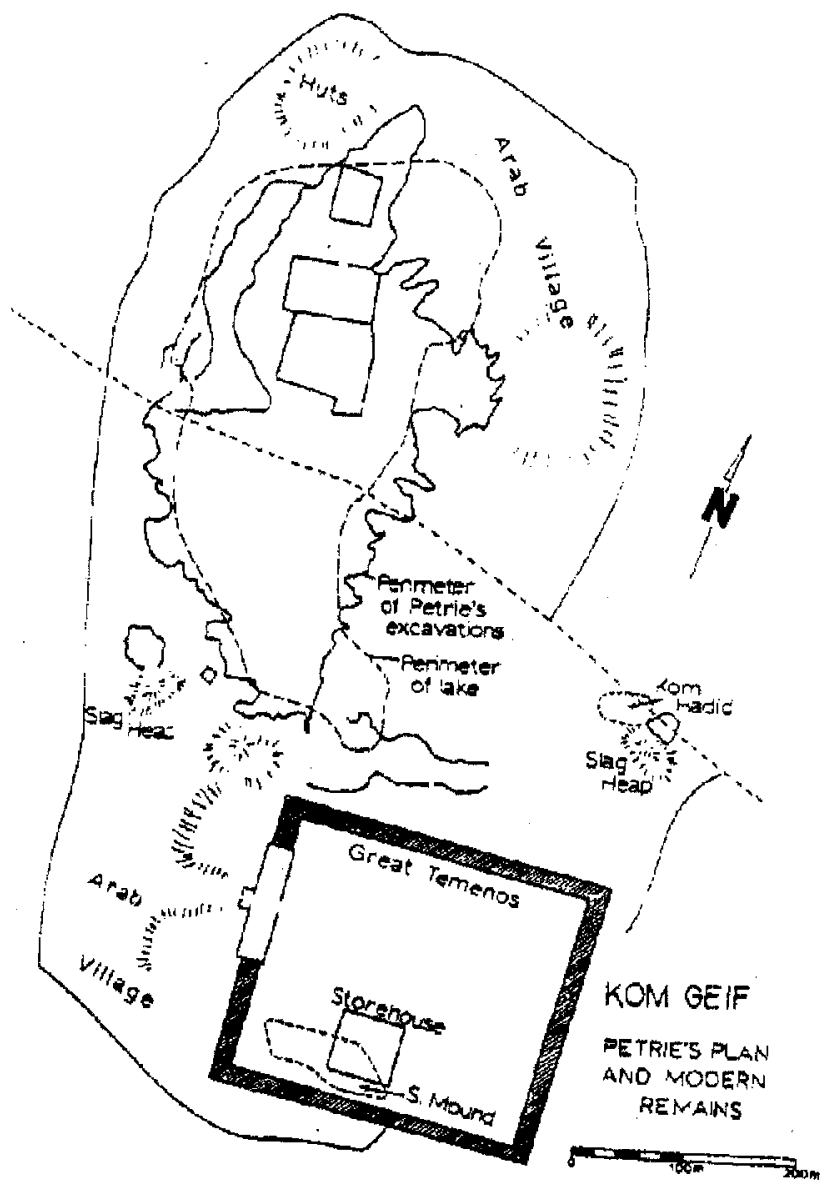

Lámina 6. Plano que refleja el lugar en que se hallaría los restos excavados y la zona de trabajo americana, el South Mound, único resto conservado en la actualidad. (Según G. Johnson).

que pasa la autopista, hay que tomar un coche e ir pasando por los cuatro pueblos que atraviesan la pista de tierra que termina en Kom Ga'if y Nebire, un poco más al norte. Son unos $20 \mathrm{kms}$., en los que se corre el peligro de que las ruedas se hundan en las profundidades de un bache o de que el conductor se vea en la imposibilidad real de seguir adelante. Tras preguntar a sucesivas personas por las ruinas - que suelen manifestar asombro e incluso diversión- se alcanza una aldea y, a mano derecha, un pequeño montículo que, según los improvisados guías del lugar, es lo que buscamos. 
A primera vista el espectáculo es decepcionante. Los $60 \times 90 \mathrm{~m}$., que medían los restos de esta estructura en $1979{ }^{40}$ se han reducido enormemente y a pesar de que la misión americana volvió a tapar todas las trincheras abiertas, se pueden observar aún algunos restos de muros de adobe, aunque no se pueda decir a qué época pertenecen, pues podrían ser modernos; pero sí se entiende ahora el porqué de la tarea de los sabajin. Los restos de adobe se van descomponiendo y mezclando en el suelo, formando una tierra muy orgánica de un color marrón y rojizo-amarillento que utilizan para fertilizar los campos circundantes, enormes extensiones cultivadas totalmente planas. Hacia el Norte se encuentra la depresión, con el lago en torno al cual una pista de tierra, la misma que nos ha traido, le circunda por la parte Oeste y comunica entre sí las restantes aldeas (foto 3). También en la zona occidental y un poco más elevado - sin duda sobre restos arqueológicos-, está el cementerio islámico actual. Por donde quiera que se pise, se camina entre fragmentos cerámicos, normalmente de factura grosera, sin decoración y de pasta rojiza. Una vez vistas las características del sitio tendemos a situar los lugares en los que se encontraron las estructuras descubiertas por las excavaciones. Pero la realidad es que el espacio excavado resulta muy pequeño, y el resto de la ciudad que hoy nos es deconocida - si tenemos en cuenta el diámetro de seis kms., de Norte a Sur que los norteamericanos han deducido por la prospección de superficie ${ }^{41}$ - es encrme.

En definitiva, parece impensable continuar hoy en día una excavación sistemática de la mayor parte del área de la ciudad, contando con los problemas físicos que plantea el terreno, debido a la cercanía del nivel freático: además, la zona de interés arqueológico que aún no ha sido tocada es la del cementerio islámico que, al seguir en uso, no permite de momento una investigación. Este cementerio islámico y el denominado «South Mound» por la misión estadounidense ofrecen los únicos restos conservados de Naucratis. Y la labor imparable de los sabajin amenaza con destruir definitivamente esta «colina sur», que como probaron las investigaciones de campo antiguas es la zona propiamente egipcia de la ciudad. Sería, pues, necesaria una excavación del área en profundidad, antes de que el único vestigio que poseemos desaparezca para siempre.

40 A. Coulson/A. Leonard, J.F.A. 1979, pág. 154.

41 W. Coulson/A. Leonard, A.J.A. 1982, pág. 373. 




Foto 3. Lago producido por la subida del nivel freático. Los restos de toda la ciudad griega se encuentran bajo sus aguas.

\section{BIBLIOGRAFIA}

ARNDT, A.A.M.D.E. Coulson: «The Development of a field Computer for archaeological use at Naukratis in Egypt», JARCE 22, 1986, pp. 105-11.

BARROIS, J.: Les irrigations en Égypte, Cairo, 1904.

Bernand, A.: Le delta égyptien d'après les textes grecs, 4 vols. - vol. II dedicado casi en su totalidad a Naucratis-IFAO Cairo, 1970.

BouRguIGNON D'ANVILLE, J. B.: Mémoires sur l'Égypte ancienne et moderne, 1766.

Butzer, K.W.: Early Hydraulic Civilization in Egypt, Chicago-Londres, 1976.

COULSON, W.D.E.: «A preliminary survey of the Naukratis region in the Western Nile Delta" JFA 6, 2, 1979, pp. 151-68.

IDEM: Cities of the Delta. Part. I: Naukratis, Malibu, 1981.

IDEM: «Investigations at Naukratis and Environs, 1980-81» AJA 86, 1982, pp. 361-80.

IDEM: «Three seasons of Excavations and Survey at Naukratis and Environs", JARCE XIX, 1982, pp. 73-109.

Du Bols-AymÉ, A./L. Cordier, et alii: Description de l'Égypte, Texte, Antiquités, Description, Paris, 1818.

EDGAR, C.C.: «Some hieroglyphic Inscriptions from Naukratis» ASAE 22, 1922, pp. 1-6.

el-FALAKI, M.: Mémoire sur l'antique Alexandrie Cairo, 1872.

Flinders PetRIE, W.M.: Ten years digging Egypt, 1881-1891, London, 1900, pp. 36-50.

IDEM: "The finding of Naukratis» Archaeological Journal 43, 1886, pp. 45-51.

Flinders Petrie, W. M./ C. Smith/E. A. Gardner/B. V. Head: Naukratis I, 1884-85, Third Memoir of the Egypt Exploration Fund, London, 1886.

GARDNER, E. A.: Naukratis, part. 11,1886 , Sixt Memoir of the Egyptian Exploration Fund, London 1888.

HoGARTH, D.G.: «Excavations at Naukratis». ABSA V, 1898-99, pp. 26-97.

IDEM: «Naukratis 1903», JHS 25, 1905, pp. 105-36.

SMITH, E. M.: "Naukratis, a chapter of the hellenization of Egypt» JSOR 10, 1926, pp. 119-206.

Toussoun, O.: Mémoires sur les anciennes branches du Nil: époques ancienne et moderne, MIE IV, 1922-23, Cairo. 